\title{
A educação libertária no boletim Cultura Popular (Lisboa, 1919)
}

\author{
Luiz Carlos Barreira*
}

\section{Resumo}

Este artigo apresenta e analisa o boletim Cultura Popular, editado pelo Ateneu Popular, instituição educacional libertária fundada em Lisboa em 1917. Esse boletim, apesar de uma existência bastante efêmera, guarda informaçóes significativas para os estudos sobre os processos de formação dos trabalhadores urbanos no limiar da modernidade capitalista, que tenham como principal fonte e objeto de pesquisa a imprensa operária. Algumas dessas informaçôes dizem respeito, por exemplo, à ênfase que os colaboradores desse periódico davam à educaçáo dos costumes, sem desconsiderarem, no entanto, a importância da instrução. Por intermédio dessa educação, redatores e colaboradores de Cultura Popular objetivavam fazer com que as classes trabalhadoras passassem a cultivar novos hábitos, como os de asseio corporal, por exemplo.

Palavras-chave: Circulação de Modelos Sociopedagógicos. Educação Libertária. Boletim Cultura Popular (Lisboa, 1919).

* Doutor em Educação (Filosofia e História da Educação) pela Universidade Estadual de Campinas - Unicamp, com pós-doutorado em História da Educação pela Universidade de Lisboa. Professor do Programa de Pós-Graduação em Educação da Universidade Católica de Santos - Unisantos. 


\begin{abstract}
O contato com o passado altera o sentido do que pode ser conhecido. Estamos sempre nos ombreando com mistérios - náo simplesmente a ignorância (fenômeno familiar), mas a insondável estranheza da vida entre os mortos. Os historiadores voltam desse mundo como missionários que partiram para conquistar culturas estrangeiras e agora retornam convertidos, rendidos à alteridade dos outros.
\end{abstract}

Robert Darnton

\title{
Introdução
}

Cultura Popular era o nome do boletim de uma instituição educacional libertária, o Ateneu Popular, sediada em Lisboa. ${ }^{1}$ A fundação dessa instituiçāo foi uma história "simples e interessante", na avaliaçâo do seu grupo fundador. Ela teve início em uma reunião, ocorrida em junho de 1917, promovida por esse grupo fundador, autodenominado Grupo de Estudos Sociais de Alcântara e constituído somente por operários. Nessa reuniáo, uma comissão, integrada por Pinto Quartim, Teixeira Danton, Sebastiāo Eugénio, Artur Freitas e Antonio Evaristo, ${ }^{2}$ foi constituída para elaborar as bases da referida instituição. $\mathrm{Na}$ reunião seguinte, essa comissão apresentou um trabalho, intitulado Bases para a criação dum Ateneu Popular, que esboçava os princípios de uma "instituição de ensino universitário e livre para a educação do povo" e que teria por objetivo "a difusão da cultura, pondo à disposiçáo de todos, o conjunto das verdades que constituem o capital intelectual da humanidade, por meio de cursos, liçóes e conferências, da biblioteca, do livro, da revista e da brochura". Deveria, ainda, "estabelecer relaçôes e confraternidade entre os sócios e suas famílias, proporcionandolhes centros de reunião e diversóes, promovendo periodicamente festas, saraus, concertos e certames artísticos, excursóes e visitas de estudo, com o duplo intuito educativo e recreativo". Deveria, por fim, dirigir-se "ao povo analfabeto, ou pouco menos". Mas não deveria pretender fazer desses analfabetos (ou quase), eruditos. Deveria, antes, "dar a todo homem a consciência da sua verdadeira situação no Cosmos e levá-lo, pela livre expansão de todas as doutrinas expostas em bases científicas, a reconstituir no seu cérebro todo o processo evolutivo e revolucionário da humanidade" (CULTURA POPULAR, 1919, p. 22). 
Fundado quando a Primeira Grande Guerra "mais feroz e desumana se manifestava, absorvendo todas as atençóes e esmagando todas as iniciativas que a ela se não destinassem ou a hostilizassem", o Ateneu teria conseguido vencer todos os obstáculos e aportar a 1919 (Cultura Popular, p. 29). Dois meses depois, viriam a público os três primeiros (e únicos) números do seu boletim, trazendo, entretanto, um apelo, dirigido a todos os seus sócios, para que eles não envidassem esforços no sentido de fazer aumentar os recursos financeiros da instituição e de elevar o número daqueles que a ela pudessem se dedicar. As atividades do Ateneu Popular se encerrariam em 1921, poucos anos depois desse episódio. As razóes então aventadas para justificar o fim dessa breve experiência serão apresentadas ao longo deste trabalho.

Apesar de o seu ciclo de vida ter sido bastante efêmero, o boletim Cultura Popular guarda informaçóes significativas para o estudo das práticas educacionais libertárias em Portugal, tema que vimos estudando e investigando há algum tempo. Informaçôes, por exemplo, sobre as excursões e visitas de estudo promovidas pelo Ateneu, que testemunham, pelo menos em parte, sobre o alcance político das açóes promovidas por essa instituição social no que diz respeito à formação das classes populares. E, ainda, algumas das representaçôes sociais dos trabalhadores urbanos do início do século $\mathrm{XX}$, presentes no imaginário das classes sociais dominantes, mas também e principalmente, nas práticas discursivas de intelectuais que se proclamavam representantes e condutores políticos daquele segmento social.

\section{Traços de um modelo de prática pedagógica: excursões e visitas de estudo}

Cerca de um ano depois da sua criação, o Ateneu Popular promoveu a sua primeira excursão de estudo. Às 9 horas da manhã do dia 7 de julho de 1918, sócios do Ateneu e suas respectivas famílias, totalizando 193 excursionistas, reuniram-se junto ao Aquário "Vasco da Gama”, de onde partiram a pé rumo à Senhora da Rocha (Linda-a-Pastora). Um estudante de geologia, chamado Mendonça, acompanhou o grupo. Nos jardins desse local, ouviram músicas populares, tocadas por um conjunto de bandolinistas que também acompanhou a excursão. Confraternizaram-se e posaram para fotos. No final do dia, todos se dirigiram para junto de uma rocha calcária, 
onde o estudante de geologia proferiu "uma interessante palestra sobre a origem e história das diferentes camadas de terra que se sobrepunham, especialmente das que se notavam naquele local, o que muito despertou a curiosidade dos ouvintes". Por volta das 20 horas, o grupo regressou a pé a Algés (CULTURA POPULAR, 1919, p. 21). Possivelmente, outras excursões foram promovidas pelo Ateneu Popular, mas apenas essa foi registrada no boletim da instituição.

São numerosos, entretanto, os registros das visitas de estudo promovidas pelo Ateneu. Entre 12 de maio e 18 de agosto de 1918, sete visitas foram realizadas. Nos registros que delas foram feitos em Cultura Popular, uma foto, feita quando da realização da primeira delas, documenta o acontecimento.

O Campo Experimental de Agricultura e o Laboratório Químico de Belém foram os locais escolhidos para a realização da primeira visita de estudo promovida pelo Ateneu Popular, que contou com a presença de 47 participantes. Essa visita teve início às 13 horas e terminou às 17 . Acompanharam o grupo: os engenheiros agrônomos, José Joaquim dos Santos e Gabriel Osório de Barros, respectivamente chefe e subchefe dos lugares visitados, e o analista consócio do Ateneu, Eduardo Osório do Campo. Osório de Barros foi o responsável por "uma interessante palestra sobre os modernos processos de culturas agrícolas e sua intensificação, demonstrando como se podem regenerar praticamente todas as culturas agrícolas com o auxílio da ciência” (CULTURA POPULAR, 1919, p. 23).

Para a realização da segunda visita, os locais selecionados foram: o Instituto Superior de Agronomia e o Observatório Astronômico, ambos situados na Tapada da Ajuda. Arsênio Torres de Mascarenhas Sobrinho, 3 o oficial do referido Instituto, acompanhou os 39 sócios do Ateneu nessa visita. Encerrada a visita ao Instituto, todos se dirigiram ao Observatório Astronômico, onde o astrônomo, Artur Teixeira Bastos, os aguardava. Bastos fez "uma ligeira, mas profunda" palestra sobre astronomia e resgatou a história da fundação do observatório. Depois da palestra, demonstraçóes e observaçóes foram feitas com "os complicadíssimos aparelhos astronômicos, entre elas a de visibilidade de manchas no astro solar, o que muito interesse despertou no espírito sequioso de saber dos ouvintes". Todos os pavilhóes do Observatório foram visitados (CULTURA POPULAR, 1919, p. 24). 
A visita ao Museu de Arte Contemporânea foi a terceira a ser registrada por Cultura Popular. Nessa visita, que durou cerca de duas horas, 45 sócios do Ateneu compareceram. O pintor Carlos Reis e o arquiteto Rosendo Carvalheira foram convidados pela direção do Ateneu para acompanhar o grupo e elucidá-lo sobre as obras de artes que ali se encontravam (CULTURA POPULAR, 1919, p. 24).

Aurélio Quintanilha, assistente de botânica e também sócio do Ateneu, acompanhou 35 sócios da instituição, dentre os quais havia algumas senhoras, na visita que fizeram à seção de botânica da Faculdade de Ciências de Lisboa. Nessa quarta visita de estudo, Quintanilha "fez uma inteligente palestra sobre botânica, intercalada com demonstraçóes ao microscópio" (CULTURA POPULAR, 1919, p. 24-25).

A quinta visita de estudo teve por cenário a estação elevatória da Companhia das Águas de Lisboa. Dela participaram 49 sócios de ambos os sexos. Iniciaram a visita pelo depósito principal, onde desembocavam as águas do Alviela, que abastecia a cidade. O engenheiro José Manuel Machado, que acompanhava os visitantes, contou-lhes a história do abastecimento de água para a cidade, desde épocas remotas, antes de ser construída naquele local a Companhia das Águas de Lisboa. Em seguida, visitaram a casa das máquinas onde lhes foi exposta, "de maneira geral e com clareza", a forma como as "potentes máquinas elevatórias" distribuíam a água pelos três depósitos que abasteciam a cidade (CULTURA POPULAR, 1919, p. 25).

Foi a bordo do vapor África, da Companhia Nacional de Navegação, que se realizou a sexta visita de estudo promovida pelo Ateneu Popular, que contou com a presença de 47 sócios, entre eles, algumas senhoras. No cais, os visitantes foram recebidos por um alto funcionário da Companhia e apresentados aos oficiais de bordo, Filipe Nascimento Freire, Valentim de Carvalho (maquinista) e Bernardino Castelhano (maquinista), que acompanharia o grupo na visita ao vapor. A visita começou pela ponte de comando e terminou na casa das máquinas, onde foi mais demorada, principalmente pelo interesse que o funcionamento das "possantes máquinas" despertou nos visitantes. Outro ponto também chamou a atenção dos visitantes: a estação de telegrafia sem fios, que muitos dos visitantes conheciam apenas pela leitura diária dos jornais (CULTURA POPULAR, 1919, p. 25). 
A última visita de estudo foi a bordo do vapor Lima, um vapor de carga e passageiros, pertencente aos Transportes Marítimos. Essa visita incluiu, ainda, uma parada no cais e na doca de Alcântara. Os visitantes, em número de 53, foram recebidos a bordo por Rodrigo Sousa de Carvalho, imediato do vapor Lima. Auxiliado por todo o pessoal de bordo, o imediato acompanhou os visitantes. Uma vez mais, a cabine da telegrafia sem fios foi o que mais chamou a atenção de todos. Nela, os visitantes "assistiram [...] à expedição e recepção de rádios, sendo-lhes prestadas explicações pelo respectivo telegrafista sobre o funcionamento deste útil aparelho" (CULTURA POPULAR, 1919, p. 25).

Em síntese, a prática das visitas de estudo promovidas pelo Ateneu Popular e registradas nas páginas de seu boletim, Cultura Popular, apresentam as seguintes características: 1) eram realizadas quinzenalmente, geralmente no período da tarde, e seu tempo de duração variava entre duas e quatro horas; 2 ) em média, 45 associados participavam dessas visitas; 3) os participantes eram de ambos os sexos, mas a grande maioria pertencia ao sexo masculino; 4) os visitantes eram sempre acompanhados por trabalhadores dos locais visitados, ou por profissionais especializados (engenheiros, arquitetos, astrônomos, pintores, botânicos etc.) especialmente convidados pela direção do Ateneu para acompanhar o grupo; todos eles, entretanto, atuavam como guias ou instrutores, davam explicaçóes sobre os lugares visitados, as atividades que neles eram desenvolvidas, o funcionamento de equipamentos neles existentes, dentre outras informaçóes; 5) em algumas das visitas de estudo, os visitantes eram também acompanhados pelo secretário-geral do Ateneu.

Ao concluir, no início de 1919, o relato dessas práticas, a redação de Cultura Popular apresentou as causas que provocaram a interrupçâo das visitas de estudo que a direção do Ateneu planejava realizar em continuidade às sete primeiras: a não-permissão do Arsenal da Marinha para a realização de visitas ao Porto de Lisboa e ao Arsenal da Marinha, tendo em vista o estado de guerra e a epidemia que se seguiu, inviabilizando a realização de visitas (CULTURA POPULAR, 1919, p. 23-25).

As práticas pedagógicas do Ateneu Popular não se limitaram, entretanto, às excursóes e visitas de estudo. Seu boletim, Cultura Popular, também fez circular saberes e opinióes, com vistas a instruir e a educar as classes populares. Nosso interesse, quanto a este aspecto, está em conhecer e problematizar as representaçóes sociais das classes populares que informam esses saberes e opinióes. 


\title{
Representações sociais das classes populares
}

Alertados por Certeau de que o consumo raramente é passivo e de que "não se devem tomar os outros por idiotas" (1994, p. 273), começamos a refletir sobre as representações sociais que os redatores e colaboradores do boletim Cultura Popular produziram sobre as classes populares, especialmente sobre os trabalhadores urbanos (público-alvo desse impresso), fazendo-as circular nesse e em outros periódicos libertários. Em um de seus escritos sobre os usos da língua, Certeau afirma que a imagem de um público passivo raramente se exibe às claras, mas "costuma estar implícita na pretensâo dos produtores de informar uma população, isto é, dar forma às práticas sociais" (1994, p. 260). Sobre essa pretensão, embora focalizando outro momento histórico, acrescenta:

\begin{abstract}
[...] levada a acreditar que seus próprios modelos culturais são necessários para o povo em vista de uma educaçáo dos espíritos e de uma elevação dos coraçôes, a elite impressionada com o "baixo nível" da imprensa marrom ou da televisão postulava sempre que o público é modelado pelos produtos que lhe são impostos. (1994, p. 260).
\end{abstract}

Instigados por essas reflexôes, pusemo-nos a pensar se elas poderiam ser aplicadas às práticas discursivas dos redatores e colaboradores do boletim, Cultura Popular. Afinal, eles também postulavam uma educação dos costumes e, nos artigos que publicaram nesse impresso, emergem imagens de uma classe popular inconsciente da exploração que sofria e que sempre se portava de maneira passiva e subserviente na relação com seus "senhores". Ao postularem uma educação dos costumes, não estariam esses redatores e colaboradores confirmando a crença em seus próprios modelos culturais? Não estariam, ainda, desconsiderando a "natureza produtiva do consumo", como diria Certeau, das classes populares, cujos interesses esses intelectuais pretendiam conhecer, defender e representar? Não estariam, por fim, reproduzindo a ideologia das Luzes do século XVIII, no limiar do XX? De acordo com Certeau, "a ideologia das Luzes queria que o livro fosse capaz de reformar a sociedade, que a vulgarizaçáo escolar transformasse os hábitos e costumes, que uma elite tivesse com seus produtos, se a sua difusão cobrisse todo o território, o poder de remodelar toda a nação" (1994, 
p. 261). Mutatis mutandis, essa crença no poder transformador da educação escolar não estaria também presente nas práticas discursivas dos dirigentes do Ateneu Popular e dos responsáveis pela edição de Cultura Popular?

No "diálogo com as evidências", ${ }^{3}$ algumas dessas nossas inquietações puderam ser submetidas à prova. Entretanto, antes de apresentarmos os resultados desse nosso "diálogo", uma advertência faz-se necessária. Não queremos, com a formulação e apresentação das questóes acima apresentadas, sugerir, e muito menos afirmar, a filiação das práticas sociais libertárias aqui focalizadas a qualquer pensamento formal, seja ele de natureza filosófica ou náo. Queremos, sim, perscrutar, tanto quanto possível e na esteira de Darnton, como os atores dessas práticas "organizavam a realidade em suas mentes e a expressavam em seus comportamentos" (1988, p. 14).

As diferentes maneiras de pensar e agir desses atores sociais são, portanto, o foco de nossas atençóes. Inventariar essas diferenças foi o objetivo precípuo traçado para esta investigação, para cuja consecuçáo as seguintes advertências foram consideradas: as de Certeau, quanto aos diferentes "lugares de fala" dos atores sociais; e as de Darnton, sobre o método da exegese e a busca de significados. Por "lugar de fala", Certeau entende "o conjunto de determinaçóes que fixam seus limites [os limites do lugar] em um encontro de especialistas e que circunscrevem a quem e como lhes é possível falar quando abordam [...] entre si” temas de interesse comum (1995, p. 222). Por isso, conclui, "por mais científica que seja, uma análise permanece uma prática localizada e produz somente um discurso particularizado" (1995, p. 222). Para Darnton, "O método da exegese pode variar, mas em cada caso, a leitura é feita em busca do significado - o significado inscrito pelos contemporâneos no que quer que sobreviva de sua visão de mundo" (1988, p. 16). É o faremos a seguir: apresentar fragmentos das visóes de mundo evidenciadas na análise que fizemos do boletim Cultura Popular.

\section{Sobre o "problema operário"}

O "problema operário" é abordado no boletim Cultura Popular por dois colaboradores, a saber: Ferreira Tomé e António Bernardo Canelas. Não foram encontrados registros biográficos sobre esses dois colaboradores. Sabe-se apenas, tomando-se o próprio boletim como fonte, que Canelas se 
apresenta como delegado brasileiro à Conferência Internacional Sindicalista de Berna, Suíça, representando a Federação Operária de Pernambuco. Quanto a Tomé, o boletim não registra nenhuma palavra de apresentação.

"Opiniōes de um desordeiro" é o título do artigo assinado por António Bernardo Canelas. "O problema operário”, o assinado por Ferreira Tomé. Esses artigos foram publicados no mesmo número do boletim, um na seqüência do outro, sendo o de Canelas o primeiro deles.

- A opinião de Ferreira Tomé

À luz das análises de Tomé, a sociedade portuguesa estaria, aparentemente, muito perto de uma completa transformação dos seus costumes políticos e hábitos sociais, sobretudo pela ação corrosiva dos hábitos e costumes da classe operária. Eis aí o "problema” operário.

De acordo com essa análise, a cooperação das classes trabalhadoras seria indispensável para a estabilidade e o progresso do Estado republicano recém-proclamado. Essa cooperação, segundo Tomé, seria o primeiro passo para a "formação de uma inteligência entre as partes (capital e trabalho)". Entretanto, "mercê de um equívoco que provinha do egoísmo individual", a sociedade portuguesa estaria a viver em um conflito permanente, que de quando em quando explodia violentamente, evidenciando, assim, o descaso em relação a toda e qualquer tentativa de construção do consenso e a opção pelo confronto violento. Esse conflito, na avaliação de Tomé, teria mantido a classe capitalista divorciada da classe operária (TOMÉ, 1919, p. 28).

Ao defender a cooperação entre as classes fundamentais da sociedade capitalista, Tomé evidencia certa representação social da classe operária que, segundo ele, impregnava o imaginário da classe capitalista. Nesse imaginário, a classe operária aparece assim representada:

[...] uma inimiga que pretendia apossar-se dos haveres que lhe pertenciam, como se a classe operária fosse uma quadrilha de salteadores sem escrúpulos que, na calada da noite, espreitasse o momento oportuno para lhe escalar o prédio, e náo como seu cooperador e, principalmente, como fator preciosíssimo da riqueza pública. (TOMÉ, 1919, p. 28). 
Ao apostar na reconciliação da "família portuguesa", ou seja, na "reconciliação" entre capital e trabalho, Tomé relaciona o que deveria ser feito pelo Estado republicano para uma rápida solução do problema operário:

[...] sistema de produção, educação técnica, reconhecimento insofismável dos diretos individuais e coletivos, seleção de competências profissionais, avaliação da capacidade produtora do país, viação, navegaçáo e todos os mais valores dignos de consideração para o inventário a fazer e pelo qual se possam obter os necessários elementos que nos permitam determinar com segurança as regras que devem assentar definitivamente o futuro de Portugal. (TOMÉ, 1919, p. 28-29).

As teses defendidas por Ferreira Tomé expressam uma clara preocupação quanto à educação escolar das classes trabalhadoras. Essa educação deveria estar a cargo do Estado republicano recém-instituído. Trata-se, portanto, da defesa de uma escola que deveria ser pública e estatal, mas não necessariamente popular. Por sua vez, a educação do trabalhador adulto, analfabeto ou semi-alfabetizado, dependeria de iniciativas isoladas da sociedade civil, como as do Ateneu Popular, por exemplo.

Além do tom indiscutivelmente pró-republicano e nacionalista do artigo de Ferreira Tomé, nele encontram-se evidências que confirmam a hipótese que orienta as investigaçóes que vimos realizando acerca das práticas (não apenas discursivas) de libertários portugueses que constituem, no início do século XX, uma rede de intelectuais interessados na formação dos trabalhadores urbanos, qual seja: a existência de uma cultura letrada que quer definir espaços sociais de adestramento para a cultura popular. Para além da educação escolar primária elementar, que outras práticas deveriam ser acionadas para que a formação do trabalhador urbano adulto (analfabeto ou semi-alfabetizado) pudesse estar centrada na educação de costumes? As universidades livres e os ateneus populares, dentre outras instituiçóes educacionais, seriam, do nosso ponto de vista, instituições estrategicamente pensadas e criadas, tendo em vista a consecução desse objetivo.

Essa parece ser a marca distintiva do discurso de Ferreira Tomé. Isto não significa, necessariamente, ser ela uma constante das práticas discursivas de todos os intelectuais colaboradores de Cultura Popular e, muito menos 
ainda, de todos os intelectuais portugueses direta ou indiretamente ligados aos movimentos libertários de então. É preciso estar atento às diferenças, para não se incorrer no erro da generalizaçáo.

\section{- A opinião de António Bernardo Canelas}

António Bernardo Canelas parece concordar com Ferreira Tomé quanto ao "equívoco que provinha do egoísmo individual", vivido pela sociedade portuguesa de então, que de quando em quando explodia violentamente, dando a impressáo de que "o homem em Portugal, tendo perdido a fala, servia-se da espingarda, do canhão e da bomba, para manifestar a sua vontade" (TOMÉ, 1919, p. 28).

Em seu artigo, Canelas (1919, p. 26) manifesta sua "opinião de socialista, sindicalista e até mesmo anarquista" sobre as correrias e tumultos, quase sempre sangrentos, que se verificam então na cidade de Lisboa, um deles por ele testemunhado. Afirma encarar esses conflitos, não do ponto de vista das conveniências políticas republicanas ou monárquicas, mas do ponto de vista do operário e do filho do povo que ele professa ser. Nas suas palavras:

[...] qualifico esses tumultos de deploráveis, além de completamente inúteis ao progresso social. Avanço esta proposição por ver que a esses movimentos de revolta não preside nenhum ideal elevado e nem ao menos um "objetivo próximo" digno de nota. Por isso é que são inúteis ao progresso social. (CANELAS, 1919, p. 26).

$\mathrm{Na}$ opiniáo de Canelas, o operariado, o povo, precisava de paz "para lutar contra os elementos exteriores" que prejudicavam o seu bem-estar e o seu livre desenvolvimento (CANELAS, 1919, p. 26). Mas esse bem-estar e desenvolvimento não seriam assegurados pelos partidos políticos existentes, pois a constituição de todos eles estaria baseada no exercício da autoridade e na garantia à propriedade privada. Para ele, apenas um partido fundado na negação da autoridade e da propriedade privada poderia assegurar ao povo a realização de suas aspiraçóes. Esse partido seria "o partido dos sindicalistas revolucionários, dos socialistas extremistas (bolcheviques) e dos anarquistas" (CANELAS, 1919, p. 27). Assim Canelas conclui sua reflexão: "Só quando 
o povo cerrar fileiras em torno do ideal libertário e realizar a socialização dos meios de produção e de consumo, só então terá uma revolta útil que lhe assegurará o bem-estar e a tranqüilidade a que almeja" (CANELAS, 1919, p. 27).

Diferentemente de Ferreira Tomé, António Bernardo Canelas atribui ao operariado, e não ao Estado (fosse ele monárquico ou republicano), a responsabilidade no que diz respeito à resolução do assim chamado "problema operário", que para ele decorria da propriedade privada dos meios de produção. Caberia ao operariado a resolução desse problema, mas essa resolução deveria, segundo ele, ser planejada e promovida por um partido político que de fato pudesse representar o operariado. Dessa perspectiva, o poder de decisão deveria ser transferido do coletivo da classe para a cúpula dirigente de um partido político que se apresentaria como seu legítimo representante. Assim procedendo, Canelas quer transferir e circunscrever a luta de classes que então se desenrolava nas ruas e em todos os poros da sociedade, para o Parlamento. "Precisamos de paz" - dizia ele em defesa do fim da luta fratricida "que maculava de sangue a tradicional e bela cidade de Lisboa” (CANELAS, 1919, p. 26).

Tanto Ferreira Tomé quanto António Bernardo Canelas, mas cada qual à sua maneira e objetivando fins distintos, são contrários à violência, à luta armada.

\section{Sobre educação popular}

De maneira distinta à dos artigos que trazem opinióes de colaboradores sobre o "problema operário" - publicados nas últimas páginas do 3o número do boletim e assinados por atores que não deixaram rastros, ou não despertaram a atenção e o interesse dos responsáveis pela historiografia produzida sobre o assunto -, os artigos que versam sobre educação popular ocupam lugar de destaque no boletim e são assinados por intelectuais que marcaram sua presença nos meios libertários, como Canhão Júnior, ${ }^{4}$ Emílio Costa $^{5}$ e J. Adolfo Coelho.

$\mathrm{O}$ artigo de Emílio Costa, intitulado "Instrução escolar e educação de costumes", abre, por assim dizer, o primeiro número de Cultura Popular. "Magna questão" é o título do artigo assinado por Canhão Júnior, que discorre sobre "o erro da república" no que diz respeito "à escola do povo". O 
artigo de Adolfo Coelho, intitulado "Educação popular", é o mais longo dos três e encerra a discussão que o Ateneu Popular promovera sobre o assunto.

- O ponto de vista de J. Adolfo Coelho

Coelho (1919, p. 17) inicia sua narrativa afirmando ser um erro "julgar-se a leitura e a escrita bases fundamentais de toda a cultura". Numerosos exemplos, extraídos da história da humanidade, são por ele apresentados. Todos eles testemunham a presença de gente que, segundo ele, desconhecia a leitura e a escrita.

A escola do ler, escrever e contar remontaria ao século XV com a presença dos mestres de ler e escrever. $\mathrm{O}$ enorme impulso experimentado pelo comércio nos séculos XVI e XVII (navegações e conquistas), a intensa troca de correspondências e os pequenos empregos surgidos nas chancelarias, entre outros fatores, teriam determinado, segundo Coelho, o desenvolvimento notável desse "ensino rudimentar", ainda ministrado por mestres particulares. Somente com Pombal, em 1772, a instrução elementar teria passado a ser função do Estado (COELHO, 1919, p. 17).

Ao comparar o programa de ensino primário de Pombal com o proposto por Alexandre Herculano, Coelho constata mudanças pouco significativas. Em linhas gerais, o ensino primário geral proposto por Herculano desdobrava-se em dois níveis: o elementar e o superior. No primeiro, o ensino deveria focalizar a leitura (de impressos e manuscritos), a escrita, princípios de aritmética (até a regra de três, inclusive) e o catecismo religioso. No segundo, gramática portuguesa (tendo o Novo Testamento como texto de referência), elementos de história pátria e de geografia, aritmética completa (elementos usuais de geometria e noçôes de agrimensura), rudimentos de física (especialmente os de mecânica), química (aplicada às artes), botânica (aplicada à agricultura) e noções de higiene. $\mathrm{Na}$ avaliação de Coelho (1919, p. 17), "este programa de ensino apenas diferia do de Marquês de Pombal, em ter a mais a parte gramatical, as regras de civilidade e maior extensão na aritmética". Estranha e acha curioso o fato de o esclarecido espírito de Herculano ter considerado esse programa de ensino suficiente para habilitar os indivíduos no desempenho das obrigaçóes que a sociedade lhes impunha como cidadãos de um país livre. Conclui, ironizando, que Herculano talvez achasse "obrigação imprescindível do cidadâo a leitura de editais e a confecção da lista de eleiçóes" (COELHO, 1919, p. 18). Ler e 
escrever continuavam sendo, portanto, as habilidades mais valorizadas pelos dirigentes políticos portugueses de então.

Também a República teria sucumbido à "magia do $a b c$ ". É o que a Reforma da Instrução Primária, executada em março de 1911 pelo primeiro governo republicano, teria evidenciado, segundo Coelho. Entretanto, no que diz respeito à educação popular e à universalização do ensino primário, a república recém-instituída pouco se diferenciava da monarquia, posto não apresentar uma proposta de reforma desse nível de ensino que contemplasse a formação do cidadão republicano, fundamentada em novos valores, em uma nova moral e em novos costumes. Pelo menos, não na prática. Para demonstrar esse seu raciocínio, Coelho apresenta as principais características do programa de ensino instituído pela reforma de 1911, informa como esse programa foi posto em prática e conclui comparando a escola primária (republicana) portuguesa com a escola primária dos Estados Unidos da América do Norte.

A República instituiu um grau de ensino anterior ao primário, o infantil, e manteve a subdivisão do ensino primário em dois níveis, o elementar e o complementar.

O programa do ensino infantil contemplava: 1) aquisição de vocabulário, preliminares de leitura e escrita (contos e lendas tradicionais), noçóes de geografia descritiva (observação de lugares conhecidos), conhecimento das autoridades locais e pessoas da terra; 2) aprender a contar até cem, a somar e a subtrair; conhecer os nomes e as utilidades dos pesos e das medidas; aprender o sentido do tamanho e proporção das coisas; adquirir noçóes sobre animais, vegetais e minerais; saber designar as principais partes do corpo humano; 3) aprender a desenhar e a modelar; 4) praticar jogos livres e ocupar-se com distraçóes agrícolas (COELHO, 1919, p. 18).

O programa do ensino primário elementar, por sua vez, deveria contemplar: 1) o ensino dos rudimentos da língua (leitura e escrita); noçóes preliminares de geografia e corografia portuguesa; moral prática; educação social; 2) as operaçóes fundamentais; o sistema métrico decimal; geometria prática elementar; 3) desenho e modelação; canto coral; 4) higiene individual, ginástica, jogos educativos; trabalhos manuais e agrícolas (COELHO, 1919, p. 18).

Por fim, o programa de ensino primário complementar. Este deveria contemplar: 1) leitura e conversação; escrita e composição; noções gerais 
da língua portuguesa; noções elementares de história geral e prática; desenvolvimento da moral prática; noçóes elementares de economia rural ou fabril; 2) noçóes elementares de aritmética, geometria, e rudimentos de ciências físico-químicas e histórico-naturais, astronomia descritiva; 3) desenho e modelação, caligrafia, fotografia, canto coral e recitação; 4) desenvolvimento da higiene, jogos e ginástica, passo e atitudes militares; para o sexo masculino, trabalhos manuais, jardinagem, horticultura; para o sexo feminino, economia doméstica (COELHO, 1919, p. 18).

Apresentado o programa em vigor da reforma republicana do ensino, Adolfo Coelho dedica-se à exposição de como esse programa foi posto em prática, destacando os seguintes aspectos: 1) as escolas primárias oficiais foram geralmente instaladas em velhos edifícios, sem condiçóes higiênicas e pedagógicas, exercendo sobre a criança um sentimento de repulsão e tédio; 2) quanto ao desenvolvimento moral da criança, observa-se a presença da prática da delação, aconselhada por professores e reforçada por uma política de favoritismo, o que contrariava o programa da reforma; 3) como previa o programa, nenhuma escola primária oficial praticava a modelagem e o trabalho manuais; 4) quanto ao desenvolvimento intelectual da criança, ao invés de liçóes morais acompanhadas de desenhos e projeçóes, como era de se esperar, dado o espírito da reforma, procurava-se assegurar esse desenvolvimento, recorrendo-se a compêndios "terrivelmente mal feitos". E conclui:

[...] a criança sai da escola, sabendo ler e escrever, mas não sabendo nem o que lê nem o que escreve; conheço casos de alguns alunos dos últimos anos dos liceus serem incapazes de redigir uma carta com o sentimento moral viciado, predominando a mentira, a dissimulação e o receio da responsabilidade (COELHO, 1919, p. 19).

Como contraponto a essa "dura" realidade educacional e um exemplo a ser seguido, Adolfo Coelho apresenta a organização de uma escola primária dos Estados Unidos da América do Norte, descrevendo-a assim: 1) sempre instalada em edifícios próprios; 2) liberdade para a escolha de escola onde estudar e concessão de passes escolares com redução de 50\% nos bilhetes de ônibus; 3) extensas áreas de recreio; 4) oficinas bem equipadas onde se ministram conhecimentos técnicos e se praticam as profissóes manuais; 5) o desenho, desde o geométrico até a modelação em barro, é base de toda essa 
modalidade de ensino; 6) a escola é de tempo parcial, mas a criança pode nela permanecer até a noitinha; 7) um lanche substancial é preparado pelas alunas mais velhas e oferecido a todas as crianças; 8) o ensino é obrigatório e gratuito; 9) a escola fornece livros, papel, lápis, tinta, carvão, madeira para as oficinas e demais materiais escolares a todos os seus alunos; 10) jornais acadêmicos peculiares a cada escola; 11$)$ auditório para a realização de conferências, de festas, de projeção de filmes e de debates, envolvendo alunos e professores. "É sem dúvida - afirma Coelho -, a este magnífico ensino que a América deve o prestigioso desenvolvimento da sua indústria e do seu comércio" (COELHO, 1919, p. 20).

É patente, nesse texto de Coelho, o fascínio que a sociedade norteamericana exercia sobre ele. É também patente a esperança que esse intelectual depositava na educaçáo escolar, que era por ele considerada uma das principais molas propulsoras do desenvolvimento econômico da sociedade. Mas essa educação não poderia deixar de estar sintonizada com os tempos modernos, ou seja, empenhada em suprir as necessidades do mundo do trabalho. Mais que instruir, essa escola deveria voltar-se para a educação dos costumes.

- O ponto de vista de Canhão Júnior

$\mathrm{O}$ artigo assinado por Canhão Júnior traz informações que, de certa forma, corroboram as teses defendidas por Adolfo Coelho sobre a educação popular em Portugal, no início do regime republicano.

Terminado o primeiro grande conflito mundial, Canhão Júnior pergunta-se se a sangrenta guerra traria "o condão de acordar de vez a consciência humana”. E, uma vez acordada, pergunta-se sobre o que seria necessário fazer para que a humanidade não viesse a incidir no mesmo erro. A resposta, segundo ele, estaria na oferta de instrução ao povo. Sem escola - pondera Canhão Júnior - "não há consciência, sem consciência não há liberdade e sem liberdade não há viver humano possível”. Assim, caberia à escola, sobretudo à escola popular, difundir e cultivar "as mais vastas e elevadas conquistas sociais” (CANHÃO JR., 1919, p. 9).

Mas "Portugal não tem escolas primárias!" - exclamava Canhão Júnior, frustrado. Isto, passados quase oito anos desde a proclamação da República. Quando a Monarquia agonizava, o partido republicano português "freqüentemente argumentava com a necessidade de desenvolver a instrução 
popular como condição prévia e indispensável da emancipação do povo" (CANHÃO JR., 1919, p. 10). Entretanto, proclamada a República, nada teria sido feito sobre o assunto. Sobre essa suposta omissão da República, assim se posicionou:

Como é possível que os republicanos hajam perdido de vista, ou colocado em segundo plano, dentro da república, aquilo que, com alta intenção e seguro fundamento, era, dentro da monarquia, o seu cavalo de batalha - o instruir e educar o povo? Por que não têm, os governos republicanos, considerado essa questão como sendo uma questão imediata e capital, se a sua resolução é a condição prévia e basilar da democracia? Ah! Evidentemente porque ainda não estamos, de fato, em república. (CANHÃO JR., 1919, p. 11).

Para Canhão Júnior, "uma república de fato é aquela que coloca em primeiro plano, à frente de todos os negócios do estado, o problema da educação nacional e, nomeadamente, a magna questão da educação popular" (CANHÃO JR., 1919, p. 11). Entretanto, essa não era a condução política que a jovem república portuguesa imprimia às reformas do ensino. Nas suas palavras,

[...] reformaram-se todos os graus de ensino, menos o do ensino primário. Reformou-se o ensino superior, reformou-se o ensino secundário e até o ensino especial. A escola primária, porém, a escola do povo, a escola-mãe, a escola da pátria e da república, o campo vasto e sacrossanto onde se semeia, por excelência, a Democracia e onde em cada ano que passa se pode elevar um pouco o nível de todo um povo - essa escola jaz ainda ao abandono, sendo sempre considerada pelo estado em último lugar! E Portugal no mapa dos países mais analfabetos do mundo continua a ser uma vergonhosa e horripilante mancha negra! (CANHÃO JR., 1919, p. 12).

Aparentemente, as classes dirigentes portuguesas estavam muito pouco inclinadas a aceitar a escolarização em massa. Mas por quê? Seriam elas, por 
ventura, simpáticas às teses defendias por Bernard Mandeville séculos atrás? No limiar da modernidade, Mandeville teria afirmado:

Para que a sociedade seja feliz e o povo tranqüilo nas circunstâncias mais adversas, é necessário que grande parte dele seja ignorante e pobre. O conhecimento não só amplia como multiplica nossos desejos [...]. Portanto, o bem-estar e a felicidade de todo o Estado ou Reino requerem que o conhecimento dos trabalhadores pobres fique confinado dentro dos limites de suas ocupaçóes e jamais se estenda (em relação às coisas visíveis) além daquilo que se relaciona com sua missão. Quanto mais um pastor, um arador ou qualquer outro camponês souber sobre o mundo e sobre o que é alheio ao seu trabalho e emprego, menos capaz será de suportar as fadigas e as dificuldades de sua vida com alegria e contentamento. (MANDEVILLE apud THOMPSON, 1998, p. 15).

Canhão Júnior (1919, p. 12) encerra seu artigo apresentando o seguinte conselho às lideranças republicanas portuguesas, confortavelmente instaladas no poder: encarar "a magna questão da educação popular", para que o povo não continuasse "no mesmo mar de sangue e de lama, amarrado à escravidão".

- O ponto de vista de Emílio Costa

A civilização de um país pode ser avaliada, segundo Emílio Costa (1919, p. 1), pelo grau de desenvolvimento alcançado por sua cultura popular. Mas o que se compreende aqui por cultura e como, segundo essa compreensão, ela se manifesta? Para Costa, cultura seria "a resultante de certa instrução e de certa educação". Esses dois elementos da cultura estariam sempre presentes em todos os indivíduos, mas a manifestação de um e outro raramente coincidiria. Esse descompasso que se produz tanto no âmbito individual quanto no coletivo seria o principal responsável "pelos desequilíbrios que se traduzem numa existência desordenada". Dessa perspectiva, a educação seria mais importante do que a instrução para a existência de uma vida harmônica. Consequentemente, a soma dos hábitos adquiridos pelo indivíduo - a educação de costumes - valeria muito mais 
do que a soma de conhecimentos ministrados na escola. A instrução escolar deveria estar a serviço, portanto, da educação. Na prática, porém, parecia ocorrer o contrário. Assim Emílio Costa interpretou a inversão desses papéis:

A preocupação principal vai para a instrução escolar, porque o que mais se estima nos indivíduos é o brilhantismo da ilustração literária, de uma erudição formalista, de uma pseudociência de aparato. É por isso que vemos tanta gente muito ilustrada, manifestando a sua cultura rudimentar, o que dá em resultado, aos países onde esta gente abunda, a cultura geral ser de grau inferior e do mesmo grau a civilização, que é a sua manifestação social. (COSTA, 1919, p. 1).

Eis a solução apresentada pelo ilustre libertário português para o problema da inversão dos papéis acima apontado: "olhar mais para os costumes do que para a escola, olhando muito por esta, sobretudo para fazer da escola uma 'escola de costumes'” (COSTA, 1919, p. 1). A educação de costumes seria, para ele, basicamente a aquisição de hábitos de higiene, sobretudo "de asseio corporal e local" (COSTA, 1919, p. 2). Para tanto, necessário seria "pregar de exemplo, em casa, na oficina, na associação, na reuniāo, em toda a parte, enfim. Depois de pregar de exemplo, pregar por palavras, a propósito, sempre e no momento em que esse mau costume se revela num companheiro, mostrando-lhe que é melhor, como nós fazemos" (COSTA, 1919, p. 2; grifos no original).

Do ponto de vista de Emílio Costa, a tão desejada emancipação das classes populares dependeria do desenvolvimento de uma cultura popular assentada na generalização da educação de costumes, ou seja, na aquisição de hábitos, sobretudo de higiene, que seriam inculcados, primeiro pelo exemplo e, depois, pela palavra.

\section{Considerações finais}

Ativemo-nos, neste texto, à descrição de algumas das práticas pedagógicas do Ateneu Popular e à análise das narrativas dos colaboradores do periódico, Cultura Popular, sempre que possível considerando aspectos relativos à materialidade do impresso. O que essa análise nos revelou? 
Primeiramente, a existência de vozes, se não dissonantes, pelo menos divergentes quanto ao entendimento e enfrentamento de questóes relativas à cultura e à educaçáo popular, especialmente sobre a participação do Estado (republicano) na oferta de ensino às classes populares e sobre as finalidades que deveriam ser atribuídas à educação escolar, entre outros aspectos. Além disso, a análise também nos forneceu indícios importantes sobre o encerramento das atividades, tanto do periódico, quanto da instituição que o editou, o Ateneu Popular.

Quanto à participação do Estado, seja no que diz respeito à resolução do "problema do operariado", seja em relação à formação do operariado com vistas à sua emancipação, não parecem ser significativas as divergências entre os colaboradores do boletim. Apenas as vozes de António Bernardo Canelas e de Emílio Costa destoam do conjunto. A deste último, não por ser contrário a tal participação, mas simplesmente por não ter se manifestado sobre o assunto. As vozes de todos eles convergem, entretanto, quanto à precedência da educação dos costumes sobre a educação escolar, questão considerada central por todos eles. Também parece haver convergência de opiniáo entre os colaboradores do boletim acerca das representaçóes dos trabalhadores urbanos. Por serem estes em sua grande maioria analfabetos, são vistos como indivíduos ignorantes e inconscientes de sua condição de "escravos", desprovidos de hábitos de higiene corporal e local, além de delatores e violentos.

As notas biográficas de Filomena Bandeira (2003a) sobre António Tomás Pinto Quartim trazem pistas que nos auxiliam a compreender algumas das prováveis razóes pelas quais as atividades do Ateneu Popular e do seu boletim, Cultura Popular, foram encerradas. Ao vasculhar indícios dessas razóes na imprensa operária do período, essa biógrafa de Quartim encontrou, na edição de 10 de abril de 1921 do jornal $A$ Batalha, algumas notas assinadas por seu biografado nas quais ele afirma que uma instituição, "nossa, inteiramente nossa", em breve ressurgiria. Com exceção de duas conferências proferidas por Emílio Costa e Farias de Vasconcelos sobre a importância da educação, no verão daquele mesmo ano, Bandeira afirma que nenhuma outra atividade dessa natureza teria sido realizada no Ateneu Popular. Feito esse esclarecimento, conclui: "Ter-se-á quedado por aqui a experiência do Ateneu” (BANDEIRA, 2003a). Para respaldar essa sua conclusão, afirma: 
Mas naquele último ano, Quartim escrevia uma brochura intitulada $O$ sindicalismo e os intelectuais, atribuindo-lhes "a responsabilidade da ignorância do povo e por conseqüência dos erros e dos actos provenientes dessa ignorância”. Chama-os, num discurso radicalizado, a colaborarem na luta sindical, em especial os médicos e os professores, dando o seu contributo à obra de regeneração social. (BANDEIRA, 2003a).

Ao que tudo indica, o Ateneu Popular teria deixado de existir, segundo Pinto Quartim, devido ao desinteresse dos intelectuais em relação à educação (conscientização?) das classes populares. No editorial do primeiro número da revista Amanhã, publicada em primeiro de junho de 1909, Pinto Quartim, ao responder à pergunta "Como há de o homem obter a verdade?", declarou:

Instruindo-se. Mas instruindo-se não no dogma, não na abstração, mas na análise, na ciência, no racionalismo; desprezando todas as idéias velhas, toda a rotina, todas as tradiçóes do passado, e vendo pelos seus próprios olhos, raciocinando pelo seu próprio cérebro, criticando, discutindo, investigando tudo e livremente, sem respeito pelas idéias puramente convencionais dominantes no nosso meio. A ciência é a redentora da humanidade. Só a ela devemos adorar, só a ela devemos obedecer porque há de ser ela que, com ternura e segurança, nos há de conduzir a essa idade feliz, a essa idade de bem-estar pressentida por todos os filósofos, sonhada por todos os pensadores. (Amanhã, 01/06/1909 apud BANDEIRA, 2003a).

Verifica-se, nessa fala de Quartim, o poder atribuído à ciência eà ilustração, mas também a crença nas instituiçóes escolares e nos meios de comunicação pelos quais esse conhecimento poderia alcançar as classes populares.

Os estudos de Guy Vincent, Bernard Lahire e Daniel Thin sobre a história e a teoria da forma escolar também contribuem, de forma bastante significativa, para a apreensão de alguns dos possíveis sentidos históricos atribuídos às práticas sociais aqui focalizadas. De acordo com esses estudiosos: 
Com a generalização das culturas escritas em campos de práticas heterogêneas, a escola torna-se o lugar cada vez mais central, o ponto de passagem obrigatório para um número cada vez maior de sujeitos sociais que se destinam a tipos de atividades e a posiçóes sociais muito diferentes. (VINCENT; LAHIRE; THIN, 2001, p. 28).

Pode-se afirmar, com base nesses estudos, que as universidades e os ateneus populares inserem-se nesse processo de "generalização das culturas escritas" verificado na Europa entre fins do século XVII e meados do XIX, muito embora tenham sido criados anos depois desse período. Mas essa é uma hipótese (de trabalho) que ainda precisa ser verificada no diálogo com outras evidências.

\section{Notas}

1 Vincula-se ao projeto de pesquisa, Imprensa periódica e circulação de modelos sócio-pedagógicos: experiências de educação libertária em Portugal no limiar do regime republicano (1911-1919), financiado pela FAPESP (2008-2010). Versão resumida deste trabalho foi apresentada no VII Congresso Luso-Brasileiro de História da Educação, realizado na cidade do Porto, Portugal, de 20 a 23 de junho de 2008.

2 Sobre Pinto Quartim, consultar Filomena Bandeira (2003a). Sobre os demais componentes do grupo, nenhum registro biográfico foi localizado.

3 Expressão utilizada por Edward Palmer Thompson (1981) para se referir à necessidade que tem o historiador de pôr à prova, tanto os pressupostos teóricos que orientam a sua prática de pesquisa, assim como as hipóteses que elabora no decorrer dessa prática, confrontandoos com as evidências, indícios, sinais, por ele encontrados nos materiais que dão suporte empírico às suas investigações.

4 Sobre Canhão Júnior, consultar Pedro Saragoça Martins (2003).

5 Sobre Emílio Costa, consultar Filomena Bandeira (2003b). 


\section{REFERÊNCIAS}

BANDEIRA, Filomena. [Verbete sobre] António Tomás Pinto Quartim [referência 694]. In: NÓVOA, António e BANDEIRA, Filomena. (Coord. geral). In: A Educação Portuguesa: corpus documental (séc. XIX$X X)$ : Dicionário de Educadores Portugueses. Lisboa: Ediçóes Asa (versão digital), 2003a.

(Verbete sobre) Emílio Martins Costa [referência 255]. In:

NÓVOA, António \& BANDEIRA, Filomena (Coord. geral). A educação portuguesa: corpus documental (séc. XIX-XX) - Dicionário de Educadores Portugueses. Lisboa: Ediçóes Asa (versão digital), 2003b.

CANELAS, António Bernardo. Opiniōes de um Desordeiro. Cultura Popular, Lisboa, v. 1, n. 1-3, p. 26-27, mar. 1919.

CANHÃO JR. Magna Questão. Cultura Popular, Lisboa, v. 1, n. 1-3, p. 9-12, mar. 1919.

CERTEAU, Michel de. A Cultura no Plural. Campinas, SP: Papirus, 1995. . A Invenção do Cotidiano: 1. Artes de fazer. Petrópolis: Vozes, 1994.

COELHO, J. Adolfo. Educação Popular. Cultura Popular, Lisboa, v. 1, n. 1-3, p. 17-20, mar. 1919.

COSTA, Emílio. Instrução Escolar e Educação de Costumes. Cultura Popular, Lisboa, v. 1, n. 1-3, p. 1-2, mar. 1919.

CULTURA POPULAR. Boletim do Ateneu Popular. Lisboa, Typografia do Sport de Lisboa, v. 1, n. 1-3, 1919.

DARNTON, Robert. O Grande Massacre de Gatos e outros Episódios da História Cultural Francesa. 2. ed. Rio de Janeiro: Graal, 1988.

MARTINS, Pedro Saragoça. [Verbete sobre] António Lopes Canhão Júnior (referência 160). In: NÓVOA, António \& BANDEIRA, Filomena (Coord. geral). A educação portuguesa: corpus documental (séc. XIXXX) - Dicionário de Educadores Portugueses. Lisboa: Ediçóes Asa (versão digital), 2003.

THOMPSON, Edward Palmer. A Miséria da Teoria ou um Planetário de Erros: uma crítica ao pensamento de Althusser. Rio de Janeiro: Zahar, 1981. 
THOMPSON, Edward Palmer. Costumes em Comum: estudos sobre a cultura popular tradicional. São Paulo: Companhia das Letras, 1998. TOMÉ, Ferreira. O Problema Operário. Cultura Popular, Lisboa, v. 1, n. 1-3, p. 28-29, mar. 1919.

VINCENT, Guy; LAHIRE, Bernard; THIN, Daniel. Sobre a História e a Teoria da Forma Escolar. Educação em Revista, Belo Horizonte, n. 33, p. 7-47, jun. 2001. 


\section{Libertarian Education in the Journal Cultura Popular (Lisbon, 1919)}

\begin{abstract}
This article presents and analyses the bulletin entitled Cultura Popular, edited by Atheneu Popular, a libertarian educational institution founded in Lisbon in 1917. Although the bulletin was short lived, it provides significant information for studies of the making of the urban working class at the threshold of capitalist modernity, whose main source is the labor press. Some of this information concerns the emphasis that the bulletin gave to education about behavior without, however, ignoring the importance of broader instruction. Through this kind of education, they sought to have the working class cultivate new habits, such as personal hygiene.
\end{abstract}

Keywords: Circulation of Social and Pedagogical Models. Libertarian Education. Cultura Popular newspaper (Lisbon, 1919).

\section{L'Education Libertaire dans le bulletin Culture Populaire (Lisbonne, 1919)}

\section{Résumé}

Cet article présente et analyse le bulletin Culture Populaire, périodique édité par l'Athenaeum Populaire, établissement d'enseignement libertaire fondé à Lisbonne en 1917. Ce bulletin, malgré son existence beaucoup éphémère, contient des informations significatives pour les études sur les processus de formation des travailleurs urbains sur le seuil de la modernité capitaliste, qui ont comme source première et objet de recherche, la presse ouvrière. Certaines de ces informations concernent, par exemple, à l'importance que les collaborateurs $\mathrm{du}$ périodique attribuaient à l'éducation des mœurs, sans mépriser l'importance de l'instruction. Avec cette éducation, les rédacteurs et les auteurs du bulletin Culture Populaire envisageaient faire apprendre nouvelles habitudes à la classe ouvrière, comme de l'hygiène corporal, par exemple.

Mots-Clés: Circulation des modèles socio-pédagogiques. Education libertaire. Bulletin Culture Populaire (Lisbonne, 1919). 


\section{Luiz Carlos Barreira}

E-mail: luizcarlosbarreira@gmail.com

Recebido em: 17/2/2010

Versão final recebida em: $28 / 3 / 2011$

Aprovado em: 10/5/2011 